\title{
La puesta en vilo de las humanidades: juego y resistencia*
}

Putting the Humanities on the Edge:

Game and Resistance

O suspense das humanidades: jogo e resistência

\section{Germán Vargas Guillén** Mary Julieth Guerrero***}

\author{
Artículo de investigación \\ Revista Colombiana de Educación, N. 72 . Primer semestre de 2017, Bogotá, Colombia. \\ Para citar este artículo: Vargas, G., y Guerrero, M. J. (2017). La puesta en vilo de las humanidades: \\ juego y resistencia. Revista Colombiana de Educación, (72), 39-63.
}

Recibido: 04/09/2016

Evaluado: 19/11/2016

* Artículo resultado de investigación del proyecto "Estudio del cuerpo y el disfrute en la fenomenología de Husserl" (2016), de la Universidad Pedagógica Nacional; desarrollado por los grupos de investigación Filosofia y Enseñanza de la Filosofia y Lúdica, Cuerpo y Sociedad.

** Profesor titular de la Universidad Pedagógica Nacional. Doctor en Educación (UPN), Mg. en Filosofía Latinoamericana. Director del Grupo de Investigación Filosofía y enseñanza de la filosofía; miembro de Husserl Circle. Correo electrónico: gevargas2@hotmail.com

*** Licenciatura en Filosofía de la Universidad Pedagógica Nacional. Miembro del Grupo de Investigación Filosofía y enseñanza de la filosofía. Correo electrónico: mjuliethguerreroc@amail.com 


\section{Resumen}

La tesis que da unidad al artículo es: El juego es el ámbito en que se pone en escena la posibilidad y el horizonte de ser. El juego es espacio de resistencia tanto al capitalismo como a la presunción de la trascendencia del télos (personal y colectivo, en la cultura, incluida la occidental). Para el desarrollo de la tesis se dan los siguientes pasos: (1) La discusión: posthumanismo, antihumanismo y humanismo, (2) la propuesta de la ética como filosofia primera en el "humanismo del Otro". (3) el esenciar y el juego como fenómenos vitales y lugares de la resistencia. A modo de colofón se aborda la pregunta ¿para qué las humanidades "aquí y ahora"? y se plantean como condición necesaria para la paz desde

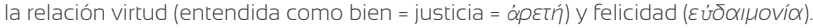

\section{Palabras clave}

Justicia, felicidad, Otro, ética, fenomenología, educación para la paz, educación moral

\section{Keywords}

justice, happiness, Other, ethics, phenomenology, education for peace, moral education

\begin{abstract}
The thesis proposed in this article is that game is a field in which the possibility and the horizon of being are put into play. Game is a space of resistance both to capitalism and to the presumed transcendence of the thelos (personal and collective, in culture, including the Western culture). This thesis is developed through the following steps: (1) discussion: posthumanism, antihumanism, and humanism; (2) the idea of ethics as first philosophy in "Humanism of the Other;" (3) the essencing and game as vital phenomena and places of resistance. As a colophon, the following question is posed: What are the humanities "here and now" for? The humanities are proposed as a necessary condition for peace based on the relationship between virtue (understood as good = justice $=\dot{\alpha} p \varepsilon t \hat{\text { ) }}$ ) and happiness

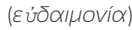

\section{Resumo}

A tese central do artigo é: o jogo é o âmbito no qual é posta em jogo a possibilidade e o horizonte do ser. O jogo é espaço de resistência tanto ao capitalismo como à presunção da transcendência do thelos (pessoal e coletivo, na cultura, incluindo a ocidental). Para o desenvolvimento da tese, foram estabelecidos os seguintes passos: (1) A discussão: pós-humanismo, anti-humanismo e humanismo, (2) a proposta da ética como filosofia primeira no "humanismo do outro" (3) o essencial e o jogo como fenômenos vitais e lugares de resistência. Finalmente, questiona-se: para que as humanidades "aqui e agora"? Estabelecendo como condição necessária para a paz desde a relação virtude (entenda-se

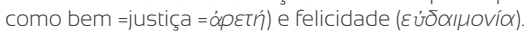

\section{Palavras chave}

Justiça, felicidade, outro, ética, fenomenologia, educação para a paz, educação moral 
El hombre [...] como ser corporal sensible está [...] determinado en su totalidad por la relación con el conflicto y la bendición generosa de la tierra. Y lo mismo es válido respecto de las dimensiones del poder y del amor en la convivencia con el prójimo. El hombre es por esencia mortal, por esencia trabajador, por esencia luchador, por esencia amante y por esencia jugador. La muerte, el trabajo, el dominio, el amor y el juego forman el complexo tensor básico y el plano de la enigmática y multivoca existencia humana.

E. Fink, Oasis de la felicidad.

\section{Introducción}

L as humanidades han sido puestas en vilo. Primordialmente, la pregunta por las humanidades nace "aquí y ahora" y más allá de plantearse en el debate de la organización y legitimidad de las disciplinas es un cuestionamiento ético y apela a la responsabilidad por el Otro y por lo otro. Las humanidades tienen la función de cuestionar, desde las márgenes, la totalidad tanto de los regímenes discursivos como de la subjetividad. Por ello, alcanzan su sentido en la defensa de la libertad de la subjetividad y en el reconocimiento de los lugares de la resistencia; no en la defensa de una esencia de hombre que se legitima a partir de regímenes discursivos sino en la actividad por excelencia en el devenir de lo humano: el esenciar, como la actividad reflexiva en las incesantes búsquedas de sentido.

¿Para qué las humanidades "aquí y ahora"? ¿Qué pueden decir y aportar a la construcción de nación, a los problemas actuales de la sociedad en Colombia, a la búsqueda de la "humanización" en medio del constante conflicto y a los proyectos de formación que se trazan bajo los ideales de justicia y felicidad?¿Qué sentido tiene hablar de "la puesta en vilo de las humanidades", en nuestro contexto?

Un reclamo vigente a la educación - hecho desde las agencias de cooperación internacional, desde los gobiernos, desde el sector productivo- se resume en un imperativo: "¡Más educación científica y tecnológica, menos humanismo y poesía!"1 . La demanda viene de consultores y ministros; se impone a través de los empréstitos internacionales. Pero, en el otro lado, "la puesta en vilo de las humanidades" viene de dentro: ¿quiénes se reconocen como "humanistas"? Esta voz es, en cierto modo, sinónimo

1 Ver: Openheimer, A. (2010). ¡Basta de Historias! La obsesión latinoamericana con el pasado y las 12 claves del futuro. Debate, 2010; la carta del ministro de Educación de Japón, Hakuban Shimomura, a las universidades de su país (recuperado de http://www.elespectador.com/noticias/educacion/japon-quiere-restringir-humanidades-su-reforma-educativ-articulo-588207). Sobre la controversia en Colombia al respecto, consúltese http:// www.semana.com/cultura/articulo/andres-oppenheimer-las-ciencias-sociales-y-el-arte/481148. 
de ingenuidad, de romanticismo, de metafísica. El programa tanto de las ciencias humanas como de las ciencias sociales deliberadamente pretende superar ese estatus; en fin, aspira a la "ciencia".

Queda, incluso, la pregunta: ¿Cuáles son las disciplinas que se ubican en uno u otro "campo", el de las humanidades y el de "las ciencias", sean humanas o sociales? Cómo se defina el título "ciencia" es un problema relevante, pero secundario frente al proyecto hegemónico. La voz "ciencia", al menos, exige que haya objeto de estudio, método, validez, historicidad y enseñabilidad. Progresivamente, tanto el método como la validez reclaman la evidencia, la contrastación empírica. Bajo estos criterios, las "humanidades" parecen tener que ser abandonadas en razón de su carácter y estructura "especulativos".

Instituciones como la Universidad Nacional de Colombia (UN) tienen Facultad de Ciencias Humanas (con departamentos de antropología, filosofía, geografía, historia, lenguas extranjeras, lingüística, literatura, psicología, sociología, trabajo social -el ordenamiento es alfabético en el sitio web-); la Universidad Pedagógica Nacional (UPN) tiene Facultad de Humanidades. ¿Indican esas denominaciones que una tiene una orientación más científica que la otra? No son solo palabras.

La UPN, en rigor, tiene Facultad de Ciencia y Tecnología, no usa un plural que incluso exigiría la variedad de disciplinas que alberga: matemáticas, física, química, biología y tecnologías (electrónica, diseño tecnológico, informática). Entre tanto, la Facultad de Humanidades tiene los departamentos de Lenguas (Español, Inglés, Lenguas Extranjeras) y Ciencias Sociales (Filosofía, Ciencias Sociales, Estudios Sociales). Con el uso del singular para una de sus facultades y la mención "Humanidades" para otra, en principio, queda en evidencia que estas no son parte de ese bloque unitario que designa en singular la expresión: "Ciencia".

Pese a que, al menos según lo muestra el organigrama, en la upN solo hay "Ciencia" cuando se alude a las disciplinas formales o las naturales, se creó un Departamento de Ciencias Sociales dentro de la Facultad de Humanidades; y allí se ubicó la carrera de Licenciatura en Filosofía. ¿Se entiende, de este modo, que la filosofía es una de las ciencias sociales? $Y$, en la UN, ¿se entiende que la filosofía es una ciencia humana, puesto que se enmarca en una Facultad de Ciencias Humanas? Y, sea que se trate a la filosofía como ciencia social o como ciencia humana, ¿cómo se valida la idea de que la filosofía sea "ciencia"2? Y, si lo es, ¿bajo qué criterios epistemológicos se entiende el título "ciencia"?

2 Es conocido el artículo de Husserl (1911) La filosofía como ciencia estricta, pero es un proyecto criticado, una y otra vez, por el positivismo, el positivismo lógico, la hermenéutica (tanto de Heidegger como de Gadamer), por el estructuralismo y el posestructuralismo, por la arqueología. ¿De qué ciencia se habla? 
Todavía hay más datos que oscurecen y confunden el panorama de las humanidades, de las ciencias sociales y de las ciencias humanas en Colombia $^{3}$. La política de Estado no solo ha eliminado la evaluación de la filosofía, de la historia y de la geografía, sino que las ha reducido instrumentalmente a "Lectura Crítica" (mediante una interpretación de la Ley 115 de 1994, vía Orientaciones del Ministerio de Educación Nacional, MEN), a través de las Pruebas Saber $11^{\circ}$, que miden "competencias"; ha convertido en obligatorias la enseñanza de: Ética, los valores y derechos humanos (Ley General de Educación 115, artículo 23), por un lado; y la Cátedra para la paz (Ley 1732 de 2014). Y, aunque es área obligatoria la enseñanza de la filosofía ${ }^{4}$ en la educación básica (al lado de la Economía y de la Ciencia Política; Ley General de Educación 115, artículo 31), en promedio, los planteles dedican 2 horas semanales en las 40 semanas del año escolar; con lo cual su ejercicio, en un cálculo optimista, no excede las 160 horas a lo largo de los 11 años del ciclo de Educación Básica.

Más allá de la consideración "local", "mundialmente" ${ }^{5}$, al menos desde la década de los años 70 del siglo pasado, la sociología, la psicología, el derecho, la historia, la antropología, la lingüística y algunas dimensiones de la crítica literaria, la musicología, etc., en cuanto se reclaman ciencia no solo abandonan el "humanismo", sino que lo combaten 6 . Entonces, la pregunta que se pone de manifiesto es: ¿Qué designa el título "humanidades"? ¿Qué disciplinas se incluyen bajo este título? ¿Qué validez tiene su desarrollo? Estas son solo algunas cuestiones que expresan la puesta en vilo de las humanidades, pero que no limitan su práctica y presencia en Colombia.

\section{Antihumanismo, posthumanismo y humanidades}

La crisis de las humanidades también se ha revelado bajo los títulos "antihumanismo" y "posthumanismo". Estos han puesto en evidencia, de muchas maneras, la necesidad de superar la creencia ingenua en la esencia del ser humano, su preeminencia como ser privilegiado de la creación, así como la urgencia de hacer "ciencia" de los fenómenos

3 Se complementan aquí algunos datos a los ya expuestos en Manifiesto contra el asesinato de la filosofía en Colombia. Véase https://profesorvargasguillen.files.wordpress.com/2014/09/ manifiesto-contra-el-asesinato-de-la-filosofc3ada-en-colombia.pdf, consultado el 31 de julio de 2016.

4 Solo desde el campo de la filosofía queda vigente la pregunta: ¿cómo se logra diferenciar "ética", que incluye "valores", de "filosofía"? Y, a su vez, ¿cómo se diferencia "educación ciudadana" y "Cátedra de la paz"? No se trata de criticar el desorden institucional en la promulgación de leyes; lo que se quiere hacer visible es la ausencia de claridad epistemológica y pedagógica.

5 Véase Wallerstein (1996), Habermas (1988) y Piaget (1973).

6 Acaso uno de las obras que lo logra con mayor encono es Sabiduría e ilusiones de la filosofía de Piaget (1965/1970, español). Otra obra, quizá más "famosa" ha sido Las palabras y las cosas de Foucault (1966/1968).

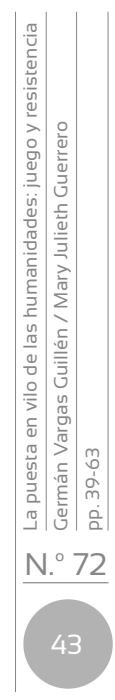


humanos: sociales, psíquicos, en fin, estructurales, más allá de la idea del hombre y de su esencia. Esta creencia no solo es fuente del antropocentrismo, es heredera de una metafísica substancialista que asume el hombre, lo humano, como algo en sí dado que tiene que ser una y otra vez actualizado. La puesta en duda de lo humano, de su esencia y de su preponderancia en la historia no solo se requirió para superar el antropocentrismo, sino que da origen a las variantes de las ciencias sociales y de las ciencias humanas; estas, a su turno, configuran el posthumanismo.

Hacen, una y otra vez, eco las observaciones de Foucault, que dejan en entredicho no solo ese "pasado" humanista, sino el horizonte tendencial de la superación de la categoría "hombre" como núcleo del pensamiento filosófico y, en especial, científico.

Por extraño que parezca, el hombre -cuyo conocimiento es considerado por los ingenuos como la más vieja búsqueda desde Sócrates- es indudablemente sólo un desgarrón en el orden de las cosas, en todo caso una configuración trazada por la nueva disposición que ha tomado recientemente en el saber. De ahí nacen todas las quimeras de los nuevos humanismos, todas las facilidades de una "antropología", entendida como reflexión general, medio positiva, medio filosófica, sobre el hombre. Sin embargo, reconforta y tranquiliza el pensar que el hombre es sólo una invención reciente, una figura que no tiene ni dos siglos, un simple pliegue en nuestro saber y que desaparecerá en cuanto éste encuentre una forma nueva. (Foucault, 1974, pp. 8-9).

¿Se expresa, de este modo, la descripción de un estado de cosas; ¿ ¿, antes bien, se indica un ideal, de una meta ambicionada? Foucault desdeñó el segundo modo de enfrentar la investigación; se limitó a testificar o testimoniar -al menos en esta obra- el pensamiento utópico, la pretensión arcóntica del saber y del sabio. Más bien, los vio como "efectos", como "emergencias". De manera aún más rotunda queda reiterada esta descripción al observar:

El hombre no existía. Como tampoco el poder de la vida, la fecundidad del trabajo o el espesor histórico del lenguaje. Es una criatura muy reciente que la demiurgia del saber ha fabricado con sus manos hace menos de doscientos años: pero ha envejecido con tanta rapidez que puede imaginarse fácilmente que había esperado en la sombra durante milenios el momento de iluminación en el que al fin sería conocido. (Foucault, 1974, p. 300).

Esto es lo que se pone en evidencia: cómo la superficie -sea que se le llame "hombre", "saber", "poder", etc.- solo es un acontecimiento; pero este, como ninguno otro, deviene; no puede, entonces, ser substancializado, ni naturalizado. Antes bien, si llega a serlo es en razón de una estructura, del devenir de la misma. 
Según Rodríguez (2010) "Este concepto desplegado por Foucault ha servido para que volviera a preguntarse por el valor de lo humano. [...] El posthumanismo nombra esa transvaloración que suspende indefinidamente la fuerza de la reflexión humanista" (p. 10). En esta vía no solo se radicalizan versiones como la biopolítica (en interpretaciones como las del mismo Foucault y Deleuze, vuelta a poner en juego por Lazzarato), sino también el modo como esta se articula en "noo-política, una política de la gestión de los signos en términos de público, que trasciende el cuerpo mismo para adentrarse en los cerebros" (p. 14).

En la exposición de Rodríguez se muestra cómo la cibernética y la biología, con su fuerte teoría de la información (procesamiento y transmisión) se han vuelto referente para pensar lo humano; al punto incluso de ver que "El mero proyecto de reproducir ciertos aspectos del pensamiento humano mediante la replicación de una estructura biológica en una estructura artificial ya no represente una afrenta para el humanismo" (p. 11), sino que "se puede afirmar que el linfocito [...] actúa según una noción de yo" (Rodríguez, 2010, p. 11).

Acaso lo que se precisa llevar a sus radicales consecuencias es la rehabilitación tanto del mecanicismo fisiocrático (tipo Saint-Simon o Comte) como la decapitación de la subjetividad por el estudio y el análisis estructural que, a su modo, conlleva el triunfo del cientificismo (sea o no positivista).

\section{Alteridad y sentido más allá de las márgenes de la totalidad}

Si el ser humano deviene un problema "metafísico", un problema específicamente filosófico, entonces él está en cuestión como ser racional, y si se cuestiona su historia, entonces se trata del "sentido", se trata de la razón en la historia. El problema de Dios contiene manifiestamente el problema de la "razón absoluta" como fuente teleológica de toda razón en el mundo, del "sentido" del mundo. Naturalmente también la pregunta por la inmortalidad

es una pregunta racional, así como también la pregunta por la libertad. Todas estas preguntas "metafísicas", concebidas en sentido amplio, las específicamente filosóficas en el habla corriente, sobrepasan el mundo como universo de las meras cosas. Lo sobrepasan precisamente como preguntas que apuntan a la idea de la razón.

Husserl, La crisis de las ciencias europeas y la fenomenología trascendental. 
Una vez ha devenido el hombre en "acontecimiento epistemológico", surge otra cuestión: ¿cómo sostener la validez de la ética? Y, aún más, ¿es posible su consideración como filosofía primera? Una y otra parecían ser el corazón mismo de las humanidades. Para responder esta cuestión se requiere dar un paso atrás, un paso previo; poner en evidencia que los problemas últimos que se plantea el ser humano son problemas metafísicos. Estos problemas son del orden de la existencia, de la historia, de Dios, de la "razón absoluta", de la inmortalidad, de la libertad. A diferencia de los problemas últimos, la fenomenología se ocupa de los primeros, de la filosofía primera, son: los de la subjetividad -que sólo es lo que es en intersubjetividad-, los de su constitución -que es inherentemente temporal, vivida en pasividad y en actividad ${ }^{7}$.

7 Por mor de la brevedad, solo en esta nota se va a explicitar la compleja relación que hay entre filosofía primera y filosofía segunda en la fenomenología de E. Husserl. Se sigue en esto la lúcida exposición de László Tengelyi (Devenires xl, 21 [2010]; pp. 115-131): ¿Qué es, para Husserl, la filosofía primera? Digámoslo en una sola frase: fenomenología trascendental; esto es, conocimiento racional de la subjetividad que, a su vez, es la región de las regiones (véase Vargas, 2014, pp. 55-74). Según la exposición de Tengelyi "Ante todo Husserl considera la fenomenología trascendental (configurada eidéticamente) como 'filosofía primera'. A la 'filosofía primera' así concebida Husserl opone la metafísica como 'filosofía segunda' en el sentido de una ciencia fundamental de la realidad" (p. 116); es decir, mientras la primera da cuenta de la emergencia de la experiencia de sentido (polo noético), la segunda alude a lo dado mismo (polo noemático). Se puede sintetizar diciéndolo así: la filosofía primera da cuenta de la constitución subjetiva-intersubjetiva del sentido (del sujeto mismo, de la intersubjetividad; del ser, de la realidad, del mundo, de Dios, de la inmortalidad), la filosofía segunda da cuenta del ser, de la estructura de(l) ser (de la realidad, del mundo, de Dios, de la inmortalidad)".

De ahí que Tengelyi enfatice: "Husserl (...) cuestiona y revisa la oposición entre la fenomenología trascendental, fundamentada eidéticamente como 'filosofía primera', y la metafísica de la facticidad como 'filosofía segunda'. Surge así una manera nueva de comprender la relación entre eidos y factum. Resultará claro que en las cosas del mundo 'las posibilidades preceden las realidades', pero en el caso del yo trascendental esta relación se invierte por fuerza. El yo se muestra como 'un factum absoluto, imborrable', y a la vez el eidos se destaca como dependiente de este factum" (p. 117). ¿Por qué este énfasis? Al menos, porque sólo hay sentido subjetivo del mundo toda vez que hay, en efecto, un mundo en verdad existente; de éste sólo se puede dar cuenta desde la experiencia subjetiva, pero tal experiencia remite y reenvía a un mundo en verdad existente. Por eso puede concluir, Tengelyi, siguiendo a Husserl: "Se debilita así la diferenciación tajante entre la fenomenología trascendental como 'filosofía primera' y la metafísica de la facticidad como 'filosofía segunda'. La edificación de la fenomenología entera depende de determinados proto-hechos o estructuras de la facticidad.

En lo esencial se trata de cuatro proto-hechos:

a) El yo como proto-factum parece tener la primacía, pero viendo las cosas de cerca se descubre que a este yo corresponden más estructuras fácticas, las cuales cuestionan tal primacía.

b) Una de estas estructuras fácticas es la tenencia del mundo (Welthabe) por parte del yo. c) En otro texto de la misma época se habla de la circunstancia de que cada yo trae consigo intencionalmente el otro, la 'interioridad del ser-el-uno-para-el-otro' (Füreinandersein) como un ser-el-uno-en-el-otro intencional (intentionales Ineinandersein), Ilamado simplemente 'el proto-hecho 'metafísico'. El hecho de un ser-el-uno-en-el-otro intencional cuestiona la primacía del yo, incluso más que el hecho de la tenencia del mundo. Cuando se califica el hecho intersubjetivo como el proto-hecho metafísico, se quiere decir que proporciona el marco general donde encuadran todos los demás proto-hechos. Esto concierne sin más al yo como proto-factum. Del hecho del ser-el-uno-en-el-otro intencional concluye Husserl: 'No sólo no soy solus ipse, ningún absoluto concebible es solus 
La metafísica como filosofía segunda exige un retroceso al sujeto como su fuente de sentido; y es ahí donde aparece el Otro, con su rostro y su reclamo, que funda la ética como filosofía primera. Como quiera que se la comprenda, la metafísica plantea el estudio de una región del ente (hombre, arte, conocimiento, etc.); mientras ética como filosofía primera da cuenta de la subjetividad dadora de sentido y, por eso, se puede concebir como región de las regiones. La ética describe y descubre la subjetividad del Otro como fuente de sentido, como subjetividad dadora de sentido y por eso es filosofía primera. La ética es, en primera instancia una relación, una relación de sentido (Levinas, 1974).

Emmanuel Levinas, en El humanismo del otro hombre (1974), propone que el problema del humanismo recae en la relación entre la experiencia, el significado, el sentido y el Otro. Al examinar la relación entre experiencia, percepción y significación, que son los cimientos de la constitución del mundo de la vida y cultural, se reconoce que es la subjetividad radical, en pasividad: "Pasividad más pasiva que la pasividad unida al acto, la cual aspira al acto de todas sus potencias" (p. 13) $)^{8}$, la principal fuente dadora de sentido. Sin embargo, ésta no se despliega de manera solipsista y no puede ser sin el Otro ${ }^{9}$, sin lo otro. La ética como filosofía

ipse $[\ldots]^{\prime}$. Así Husserl dice inequívocamente que un yo trascendental sólo es concebible en el marco de un ser-el-uno-en-el-otro intencional. Algo parecido vale para la tenencia del mundo. El mundo, que el yo tiene, nunca se restringe a la esfera de propiedad de un sujeto singular; más bien el mundo supone siempre co-sujetos (Mitsubjekte), con los cuales el yo mantiene un ser-el-uno-en-el-otro intencional.

d) El cuarto proto-hecho, puesto de relieve por Ludwig Landgrebe, es la teleología de la historia (Geschichtsteleologie), la cual no sólo es mencionada a principio de la década de 1920, sino además en textos posteriores, y en algunos casos Husserl la vincula con una peculiar idea de Dios. También esta teleología de la historia presupone una comunidad intersubjetiva" (pp. 218-219).

8 En Vargas (2016b; p. 103n), hemos expuesto nuestra duda sobre la relación de Levinas con Ideas II de Husserl; sobre todo en vista de la pasividad, tal y como emerge en esta obra. De lo que no cabe duda es de la importancia que Levinas le dio al título pasividad (véase Hofmeyr, 2009).

9 ¿Qué hace el yo trascendental con respecto al yo empírico? ¿Cómo opera el uno con respecto al otro? En síntesis, el yo empírico en su fluir tiene una experiencia patética de la existencia; el trascendental lo toma como objeto de contemplación, primero; y, luego, como objeto de reflexión. No solo ve qué hace, en descripción estática, sino que reconstruye cómo, en descripción genética, se ha constituido hasta llegar a ser como es, no solo en términos de ideas, valores, actitudes; sino también en usos: tamaño, talla, flexibilidad, etc. No se puede decir mecánicamente que "el que piensa bien, obra bien"; pero sí es posible prever que la reflexión del yo trascendental no solo propicia comprensión (de o sobre el empírico), sino que desde ella es posible al menos trazar nuevas vías de acción (proyectos, planes, acción estratégica, puntos de vista para la "negociación" con el otro, con los otros, en el mundo de la vida social, económico y cultural). Aquí de lo que se trata es de comprender la constitución de la persona, de la personalidad y sus posibilidades de abrir mundo; desde luego, se puede hacer una descripción de y para cada quién, pero también se apunta a las estructuras más generales de la intersubjetividad. ¿Tiene esto que ver con el ascenso a la generalidad? ¿Con la racionalización que, a su turno, deviene tras el desencantamiento del mundo? Es tal vez la posibilidad de la crítica desde la teoría de la acción comunicativa al proyecto de formación en el sentido hermenéutico que toma Gadamer de Hegel (Habermas, 2014, p. 230).

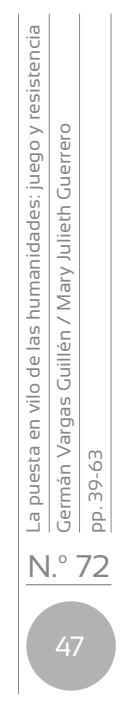


primera reconoce que sin el otro no puede haber despliegue de ser. Antes de ser un ser para la muerte soy un ser para el Otro, que es quien posibilita y crea todos mis horizontes de realización. La ética como relación de sentido atraviesa constitutivamente el mundo cultural, además, ella es el polo fundante que cuestiona, desideologiza o reconoce lo diferente, lo que se sale del orden de las cosas, de las jerarquías, de la totalidad de los significados y de la ideología.

Desde la relación ética se potencian los significados de la realidad y desde dónde se devela o desencubre el sentido de la "humanidad". Si los significados que se instalan en la cultura surgen de la experiencia -que a partir de la percepción y de la toma de conciencia de sí, del sujeto reflexivo, se crean sobre el mundo-, entonces esta -la significación- es limitada; el significado y el sentido de la realidad también. A través de la experiencia, el sujeto capta en la percepción datos que, a partir de signos y metáforas, significan; no obstante, la significación es más pobre que la percepción. Significamos menos de lo que percibimos y por ello el sentido no se agota. Requerimos considerar lo Otro, lo ausente, lo diferente, lo que se escapa a la reducción dentro de la mismidad de la totalidad.

La humanidad no está atrapada en los significados de una cultura, en la historia, ni en una época determinada. Al contrario, en los contenidos percibidos como datos hay fugas de sentido que más allá de su aparición -más bien en su ausencia-, confieren significación (Levinas, 1974, p. 18). El humanismo surge para otro tiempo, más allá de la inmediatez, del determinismo y de la necesidad que condicionan por completo el pensar. El humanismo para el "Otro", se refiere a este en cuanto está completamente ausente y presupone la responsabilidad en todas las configuraciones del mundo actual.

El humanismo exige volver a la "huella" y "obra" para transformar el mundo extraño en alteridad. Por un lado, la huella en la cultura "es la inserción del espacio en el tiempo, el punto en el que el mundo se inclina hacia un pasado y un tiempo [...] es la presencia del que, hablando propiamente, no ha estado jamás aquí, del que siempre es pasado" (Levinas, 1974, pp. 79-80). En esa dirección, "el otro es un puro agujero en el mundo. Procede de lo absolutamente Ausente" (Levinas, 1974, p. 73). El papel de la

\footnotetext{
La profesión: ¿cómo se transmuta la ética (con su base religiosa-soteriológica) en formas de vida de la profesión? De lo que se trata con esta transmutación es de ver cómo la profesión no es más un sentido de salvación. Con ello deviene un sentido si se quiere secularizado de la ética, aplicada al trabajo, y en relación con los otros, con los miembros de los colegios profesionales.

¿Cómo se da el paso del ascenso a la generalidad (Hegel) -que implica un modelo religioso de o para la formación- a un estilo de vida orientado por una racionalización de la profesión en el mundo de la vida social y político?

Esta manera de pensar y sobre todo de enfrentar la profesión seculariza el llamado ascenso a la generalidad.
} 
reflexión es, entonces, hallar el sentido que se instaura en una ética del humanismo del Otro, para el Otro: del que ha sido excluido, marginado, invisibilizado $^{10}$. Así, este humanismo se debe considerar como intempestivo porque irrumpe en las significaciones predominantes $y$, a partir de la subjetividad creadora, de la libertad de la subjetividad, se convierte en alteridad.

Ni las cosas, ni el mundo percibido, ni el mundo científico permiten volver a encontrar las normas del absoluto. Como obras culturales, están bañadas por la historia. Pero las normas de la moral no están embarcadas en la historia y la cultura. Tampoco son islotes que emergen de ellas ya que hacen posible toda significación, también la cultural, y permiten juzgar otras culturas. (Levinas, 1974, p. 71).

Desde la ética, la responsabilidad precede a la libertad. Y esta responsabilidad es, de todos modos, "pasividad radical de la subjetividad con la que recuperamos la noción de 'una responsabilidad que desborda la libertad' (cuando sólo la libertad debería poder justificar y limitar las responsabilidades)" (p. 102). ¿Por qué? En último término, porque la libertad es, con mayor o menor grado de claridad, una toma de conciencia de las propias posibilidades; de la intervención de la voluntad y de la decisión en la toma de decisiones ante las mismas; de un querer que motiva la acción. En cambio, en pasividad $^{11}$, oscuramente, inconsciente o preconscientemente, incluso sin quererlo, todo cuanto se decide es, a su turno, algo de lo cual cada quien se hace cargo; así "... [e]s la responsabilidad desbordando la libertad, es decir,

10 Cabe recordar, solo de paso, que en Totalidad e infinito Levinas insiste en que el otro se manifiesta en: el pobre, la viuda, el huérfano, el extranjero; pero el Radicalmente Otro es un reclamo que viene de lo Alto, del Altísimo. (Véase Vargas, 2014, pp. 241-265).

11 ¿Remite la distinción pasividad-actividad a un dualismo? Lo dado en pasividad en algún momento previo ha sido constituido activamente; pero se le llama "pasiva" a cualquier dación o donación que toma el carácter de trasfondo (o background) que no solo sirve de referente para la comprensión actual, sino que se puede, una y otra vez, revivificar en distintas funciones que comprenden el sentido del darse fenoménico actual, y desde allí permite la configuración de un nuevo sentido a la experiencia presente-viviente, para tematizar lo que se ha naturalizado.

Las ideas, los conceptos y, en la mayoría de los casos, las nociones se viven en y como trasfondo de pasividad. Por ejemplo, las ideas de lo varonil, de la masculinidad, del género: se viven activamente en pasividad. ¿Cómo se relaciona uno con otros, varones con mujeres? ¿Cómo se valoran entre ellos: gestos, actitudes, comportamientos? Todo esto más que una reflexión activa, actual, actuante: es o se vive como comportamiento. Incluso esta panoplia pasiva, desde o en pasividad, orienta anónimamente, cómo se ama, cómo se acoge al otro, cómo se despliega, se pliega o repliega, la subjetividad en sus relaciones con el otro. Por eso es posible sostener que lo más importante de la experiencia de mundo se vive en pasividad (Vargas, 2016a, p. 9).

Ahora bien, todo lo que se da en pasividad llegó a ser constituido activamente: cada quien aprende o se comunica o constituye sus "valoraciones" de los negros, de las mujeres, del poder, de la humildad; etc. En este sentido se mantiene y se preserva la tesis: “¡Conocer es reconocer!". Entonces no se puede aceptar la presunción de que se trata de una disyuntiva: pasividad-actividad, más bien, si se quiere, una y otra son dos caras de una misma moneda. Solo que el otro, el radicalmente otro, se da como un trasfondo de pasividad desde el cual lo tengo que retrotraer para explicitarlo en el reclamo que me hace su seren-el-mundo; esto es, la radicalidad de su rostro.

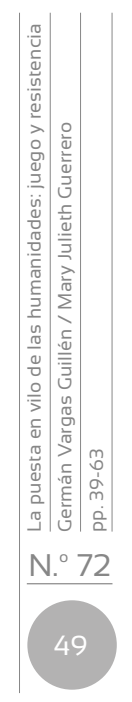


la responsabilidad por los otros. Es huella de un pasado que se niega al presente y a la representación, huella de un pasado inmemorial" (Levinas, 1974, p. 104). En último término, la responsabilidad revela lo que cada quien es y hace, el modo como se hace cargo de sí, de los otros, del mundo.

En este contexto, dada la transformación de la ética en filosofía primera, la función del humanismo consiste en hacer brillar el sentido más allá de las significaciones, que toman valor a partir de la totalidad; pues, "la significación -en tanto que totalidad iluminadora y necesaria a la percepción misma- es un ordenamiento libre y creador" (Levinas, 1974, p. 28). En la totalidad y en la multiplicidad existen obras culturales (como cuadros, poemas, melodías) que han sido creadas a partir del pensar anterior a la función de la significación; y, en ese sentido, la desbordan. Este desbordar la totalidad se constituye desde el gesto creador de la subjetividad, es decir, sobre la evocación de obras culturales previas, en función del advenimiento de lo inédito, de lo inesperado. Es este advenimiento el que incluye lo oculto, lo marginado, lo invisibilizado; en consecuencia, crea una visibilidad que incluye.

La pregunta por el sentido busca lo inédito, lo todavía-no, en un mundo que traspase las huellas humanas y que no falsee la identidad de las significaciones; en fin, un mundo puro de toda ideología (Levinas, 1974, p. 116).

Nuestra tesis es que las humanidades traen a la reflexión el resto, lo olvidado, lo metafísico (último) y el fundamento (la subjetividad, lo primero); se orientan a desplegar una visibilidad en y sobre lo que se ha invisibilizado. Las humanidades (la metafísica, la ética, en fin, la filosofía; la literatura, la pintura, la danza, la música, la arquitectura, en fin, el arte) suspenden la pretensión de cientificidad (que no de rigor o de estrictez) y ponen en despliegue el desocultamiento de lo humano, la visibilización del invisibilizado.

\section{El juego y el esenciar}

Las acciones en la vida cotidiana están encadenadas al fin último, que independientemente de cómo se interprete, conduce el trabajo serio de la vida. El ser humano, a diferencia de las plantas o los animales, se pregunta por el sentido de su existencia, "queremos comprender para qué estamos en la tierra. Es una pasión inquietante la que lleva al hombre a la interpretación de su vida terrena: la pasión del espíritu" (Fink, 1966, p. 13). Estas preguntas y el deseo de "hacer la tarea" mueve el trabajo humano y con ello aparecen múltiples interpretaciones respecto al fin último. "Encontramos también, como rasgos característicos del proyectivo estilo de vida humano, la inquietud, la precipitación, la atormentadora incertidumbre" (Fink, 1966, p. 14). En todo esto se inserta el juego de una manera peculiar que merece consideración, pues el juego es diferente a esta forma futurista de 
concebir la existencia, no se ubica en la cadena de los fines, no se preocupa por la interpretación que de la felicidad se tiene, más bien es como un "oasis de felicidad", que refleja de una manera muy peculiar la estructura de la existencia (Fink, 1966, p. 14).

Hay múltiples razones por las que se pueden considerar el juego y el ocio como lugares por excelencia de la resistencia. El análisis realizado por Eugen Fink (1966) permite comprender el fenómeno lúdico y el despliegue de modos de ser de la vida humana bajo la estructura del juego o el despliegue del juego según la estructura de la vida humana. El juego no es marginal al trabajo y a la vida seria aunque así se le considere. Las antítesis "trabajo-juego", "juego y seriedad" no reflejan el impulso vital de la fuerza con la que se promueve el juego. Este es un fenómeno vital y como tal todos hemos tenido experiencia de él. Cada individuo despliega modos de ser en los distintos momentos del juego que acontece en las dimensiones temporal, intersubjetiva y de gozo. Hay máquinas de producción de juguetes a gran escala y una industria del juego y del deporte de alcance mundial. Hay campos de juego, estadios, costumbres lúdicas nacionales e internacionales, etc.

En el juego no solo se desarrolla un simple gozo de la acción lúdica, su realización refleja un trato interpretativo de la vida humana que acontece en un horizonte comunitario y es como un "oasis de felicidad que nos sale al encuentro en nuestra brega por la felicidad" (Fink, 1966, p. 14). El juego es un fenómeno existencial que tiene relación no solo con lo imaginario, con lo temporal ("el juego nos regala presente"), con el impulso creador y con la alegría que se busca, es también relación con el otro, con el juguete y con la apariencia; se convierte en una metáfora del mundo, "el juego humano es la acción simbólica de un hacer presente sensiblemente el mundo y la vida" (p. 29).

De vez en cuando el hombre tiene que librarse del yugo del trabajo, librarse una que otra vez de la presión de la brega tenaz, sacudir el peso de los negocios, desligarse de la estrechez del tiempo dividido para tener un trato más laxo con el presente. (p. 8).

El juego aparece no solo como ocio y gozo frente a la vida y a los ideales de vida que buscan la "felicidad", independientemente de la interpretación que de esta se tenga. En el despliegue temporal del juego acontece la alegría y se busca, se propone prolongarla y también se programa, pero no se reflexiona sobre ella. El individuo en el juego no está reflexionando directamente sobre el mundo o sobre su felicidad, pero tampoco está determinado por fuerzas ajenas a lo que es él. El juego es, también, un parecer entre la irrealidad y la realidad: "prácticamente vivimos en el juego" (Fink, 1966, p. 7). 


\title{
De la areté a la eudaimonía: lo puesto en juego
}

\author{
Todos aspiramos a la eudemonía, pero de ningún modo estamos \\ de acuerdo sobre lo que ésta sea. No sólo tenemos la inquietud \\ de la aspiración que nos arrastra, sino también la inquietud de la \\ interpretación de la verdadera felicidad.
}

E. Fink, Oasis de la felicidad

¿Qué va de una educación moral o ética a una educación para la paz? Mientras la primera se orienta a la virtud (entendida como areté [ $\dot{\alpha} \rho \varepsilon \tau$ r $]$, bien = justicia), esto es como fin, la segunda se plantea pragmáticamente lograr que los sujetos en su interacción (siempre conflictiva) puedan lidiar con el conflicto por los medios más racionales o más razonables (a esto, y sólo a esto, es lo que llamamos educación para la paz). En la primera puede quedar un resto moralista e incluso moralizante; en la segunda se apela al sujeto en su estructura pulsional (Hybris, pulsión, impulso, tendencia; Der Trieb), en su emotividad (pudor) previo al desenvolvimiento del hecho o de la ejecución de la decisión y a su evaluación desde el punto de vista de sus emociones (vergüenza, Aidós): los dos lados o caras de Aidós (pudor y vergüenza); esto permite razonablemente entender las leyes de los dioses (Thémis) y de los hombres (nómos) derivadas de la costumbre; hasta llegar no solo a evaluaciones, sino también a interpretaciones (Dike: justicia, principio de justicia, ajuste).

Mientras en la educación moral se suele hablar de etapas (como Kohlberg à la Piaget), al lidiar con el conflicto -o educación para la pazpor los medios más racionales o razonables se busca establecer la génesis en cuanto un ponerse ante la experiencia originaria (Urerfahrung). Se trata, como y con el tiempo lógico, de ver el advenimiento del Otro, del Radicalmente Otro, en el juego, en el juego de la existencia; más allá de la seriedad de los negocios, más allá del juego que suspende y niega el ocio.

Todavía en el título educación moral no solo está la herencia kantiana de los alcances, también de las limitaciones, de la razón, sino que de distintos modos los imperativos morales -incluso en la versión de imperativos categóricos- vuelven a hacer presencia. Si se piensa en la sentencia kantiana según la cual la persona del otro es en sí misma un fin y nunca un medio; o, si se trae a colación el obra de modo tal que la máxima de tu acción pueda convertirse en norma universal; en cualquiera de estas formulaciones parece que es la razón la que formalmente descubre y pone de presente al otro.

Más allá de este formalismo, en la perspectiva moral, incluida la educación moral, el humanismo del Otro (en el sentido levinasiano del término) busca, principalmente, la realización de la justicia en un hori- 
zonte intersubjetivo en el que se reconoce que el Otro que no está incluido o reconocido en la esfera de la "totalidad", definida "totalitariamente" esta desde algún lugar hegemónico de enunciación (Occidente; una etnia; el Estado, el Gobierno, la ley, los tribunales y las altas cortes; los varones, los blancos, los heterosexuales, etc.).

A su turno, la búsqueda de la areté (en la perspectiva de Kohlberg) tiene como fin último el bien, el conocimiento del bien y su realización mediante la justicia; según esta perspectiva "la justicia es un asunto de derechos humanos y universales" (Kohlberg, 1981, p. 102). Es el valor moral supremo de la sociedad y del individuo, no un conjunto de reglas, sino un principio moral; es decir "un modo de elegir que es universal, una regla para elegir que quisiéramos que la gente adoptara siempre, en todas las situaciones" (p. 102).

Al abordar la búsqueda de la areté, las humanidades se enfrentan a la pregunta de si acaso es posible enseñarla y se relaciona, entonces, con la formación de metas morales. La justicia no puede pensarse como un valor más en un "paquete de vicios y virtudes" con el que se exhorta tanto a niños y niñas como a adultos a plantearse metas morales y así formar su carácter moral.

Aunque de la mano de la ciencia es posible hablar sobre relaciones causales o sobre relaciones entre medios y fines, se debe plantear desde otra dimensión (más humanística), a saber: la reflexión en torno a los fines y valores en sí mismos (Kohlberg, 1981, p. 94) que conducen a la realización de la justicia. Según Kohlberg, la virtud, en su despliegue como el bien y como la justicia, se puede realizar y aprender tomando como base las etapas de desarrollo moral ${ }^{12} \mathrm{y}$ teniendo en cuenta que:

1. La virtud es siempre la misma forma ideal, independientemente del clima o de la cultura.

2. El nombre de esta forma ideal es la justicia.

3. La virtud no solo es el bien, sino también el conocimiento del bien. "El que conoce el bien, elige el bien".

4. La clase de conocimiento del bien en que consiste la virtud es el conocimiento o intuición filosófica de la forma ideal del bien, no una opinión acertada o la aceptación de creencias convencionales.

5. El bien se puede enseñar, pero sus maestros deben ser en cierto sentido filósofos-reyes.

12 Las etapas que Kohlberg menciona son: Etapa 1: La orientación, el castigo y la obediencia. Etapa 2: El relativismo instrumental. Etapa 3: La orientación a la aprobación, el afecto y la ayuda. Etapa 4: La orientación al mantenimiento de un orden social, de reglas y derechos. Etapa 5: La orientación al contrato social. Etapa 6: La orientación a principios morales universales (1981, pp. 104 y ss.).

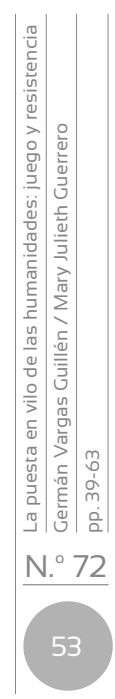


6. La razón por la que el bien se puede enseñar es porque siempre lo hemos conocido vagamente o a un nivel elemental, y su enseñanza es más un llamado que una instrucción.

7. La razón por la cual creemos que el bien no puede ser enseñado es porque el mismo bien es conocido de distintos modos a diferentes niveles, y la instrucción directa no puede darse en diferentes niveles.

8. La enseñanza de la virtud es el planteamiento de preguntas y el señalamiento del camino, no el dar respuestas. La educación moral es conducir a los hombres a elevarse, no a la instrucción en sus mentes de un conocimiento que no estuviese allí antes (Kohlberg, 1981, pp. 94-95).

Florece, entonces, un problema para la educación moral que implica el humanismo del Otro: la realización de la justicia trae consigo el despliegue del bien y exige el conocimiento de éste. No puede seguirse entendiendo la justicia como el fruto de la adquisión de un "paquete de vicios y virtudes", sino como un principio moral, que es "un principio para resolver exigencias o aspiraciones que compiten entre sí" (Kohlberg, 1981, p. 102).

La justicia trata la exigencia de cada persona con imparcialidad, independientemente de la persona. Un principio moral no es sólo una regla de cómo actuar, sino una razón para actuar. Como razón para actuar, la justicia es Ilamada respeto por la gente. (p. 103).

Aquí se requiere girar la mirada de la educación moral y empezar a observar cómo emerge la aspiración de una educación para la paz; a su modo es un giro de la metafísica tradicional a la ética, que funda el sentido de lo humano. De ahí que se requiera dar lugar a tres pasos: (1) el abandono de la idea de la paz como estado y su comprensión como proceso; (2) el reconocimiento de la imputabilidad como asomo de la autocomprensión del sujeto como humanamente responsable; (3) la vergüenza como "ámbito de la evaluación moral" de las acciones humanas.

\section{Polemos frente a paz perpetua}

Dos ideas, al menos, ofrece la tradición filosófica que permiten relativizar la metafísica con respecto, por un lado, al conflicto o la guerra (polemos); y, por el otro, con respecto a la paz. La primera es la observación de Heráclito según la cual "Guerra (polemos) es padre de todos: a unos ha acreditado como dioses, a otros como hombres; a unos ha hecho esclavos, otros libres" (DK 22 в 53). De lo que se trata es de ver que nunca se elimina la estructura de confrontación o discordia (en DK 22 в 8 se haya la observación: "Todo sucede según discordia") sobre la cual se articula la 
experiencia humana de mundo; antes bien, un conflicto se supera (Aufhebung, en el sentido hegeliano del término) y en el horizonte se descubren o se plantean o bien unos nuevos, o bien antiguos conflictos que yacían en segundo o en tercer plano, en razón de la preeminencia de las "angustias" o las "afugias manifiestas". Suponer, por tanto, que hay eliminación de los conflictos implica una actitud según la cual estos son un estado; mientras, en sí, ellos siempre son procesos. En adición a esto, si se substancializa el conflicto, este adquiere una valoración metafísica-moral: aparece como una expresión o, incluso, como una encarnación del mal.

La paz, a su vez, como lo indicó Kant (1795; 1972 en español, p. 215), siempre corre el riesgo de ser reducida a la paz de los cementerios $^{13}$. En rigor, esto -y solo esto- es "La paz perpetua". Para que la paz sea perpetua hay que llegar a perpetuarla; alguien la tiene que perpetuar. Se crea así la ilusión de que alguien la puede definir y, sobre todo, la tiene que imponer. Se puede, entonces, crear "Ministerios para la paz, para el posconflicto", burocratizar la administración de la paz. Esta es una expresión de la metafísica que, de nuevo, vuelve a definir la paz como una substancia; solo que ahora esta es, según una cierta valoración metafísica-moral, una expresión o incluso una encarnación del bien. Se torna, entonces, en una paz totalitaria, excluyente, hegemónica, impositiva.

Una como otras ideas, substancializadas, conciben estados, no procesos. Lo que cambia la perspectiva y dinamiza o puede dinamizar cambios de mentalidad en los procesos educativos es aventurarse a promover, en rigor, una ética sin metafísica. Esta implica asumir, pensar y actuar: sobre lo que hay, a saber: naturaleza humana en conflicto; con aspiraciones de poder vivir: con los otros, en medio de los otros y, en muchas ocasiones, a pesar de los otros. A esto, sin pretensiones últimas, metafísicas, es a lo que una y otra vez redefinido, situacional y contextualmente, en aras de la comprensión, se puede llamar "paz". La paz se reduce -nada más, nada menos- a una idea regulatriz, una aspiración, un télos: siempre pretendido, nunca alcanzado plenamente.

¿Qué exige esta "formación"? En primer lugar, la capacidad de cada quien de detectar lo que le fastidia, lo que le molesta, en fin, lo que lo hace infeliz, de un lado; pero, de otro, lo que le agrada, lo que le satisface, en fin, lo que lo puede hacer feliz. Pero resulta que esto último no se puede hacer con desmedro de los otros. De nuevo, es lo que Kant identificó bajo el título de sociable insociabilidad; y, aun, de idea del progreso en un sentido indefinido. Ahora bien, esta identificación requiere, en segundo lugar, explicitar motivos y razones. Que esto, en tercer lugar, ocurre con los otros

13 “'A la paz perpetua'. Esta inscripción satírica que un hostelero había puesto en la muestra de su casa, debajo de una pintura que representaba un cementerio, ¿estaba dedicada a los hombres en general, o bien quizá a los gobernantes, nunca hartos de guerra, o bien quizá a los filósofos, entretenidos en soñar el dulce sueño de la paz?" (Kant, 1972, p. 295). 
y en función de la acción estratégica, es una consecuencia de buscar ese poder vivir con los otros, en medio de ellos, a pesar de ellos. Y esta "formación" no se da al sujeto; él tiene que desplegarla, hacerla suya, ganándose un "espacio" en el mundo de la vida social.

La educación para la paz puede ser articulada sobre la base de dos "polos": la identificación de conflictos y el análisis de la falibilidad de las soluciones. ¿Qué función concierne al maestro? En esencia, diseñar ambientes para la identificación de conflictos y contribuir a la evaluación de argumentos en su presunta solución.

\section{Imputabilidad-responsabilidad}

El conflicto y las diversas formas de resolución requieren que los sujetos, uno a uno, se hagan conscientes o comprendan que en cada situación o circunstancia en la que se hallan tienen que asumirla como y en primera persona. Incluso, frente a lo vivido cada quien está en posición de afirmar: mea res agitur. Un individuo que da por sentado que las cosas "pasan" o "le pasan", sin que tenga que responder por ello, poco a poco se habitúa al "cinismo", se torna un "cínico"14; en el otro extremo, en cambio, aparece el melancólico: el que o bien "se echa encima toda la responsabilidad" por el mal del mundo o "sufre" por todos "Ios males del mundo". Hacer la profilaxis, como primera persona, de lo que le viene a uno de imputable en una circunstancia es, al mismo tiempo, entender qué les concierne -si se quiere: en proporcionalidad- a los otros. Esta profilaxis permite asumir aquello por lo que tiene responder y aquello por lo que tienen que responder otros. Desde luego, aquí se incluye la imputabilidad-responsabilidad por los actos tanto voluntarios como por los involuntarios.

El diseño de un ambiente de aprendizaje -alcance de la actuación del docente- implica un "arreglo metodológico" (que tiene, entre otros ingredientes: la actuación del maestro, los libros, las redes, la interacción entre pares, el salón, los instrumentos musicales, los lugares de esparcimiento) que procura reducir la incertidumbre o minimizar la contingencia. Se trata de no dejar al mero azar la respuesta, que puede construir el estudiante, a preguntas tales como: ¿Con qué ediciones (textos, traducciones, impresión, tipo de papel, etc.) se encuentra y cómo los puede usar para su resolución de preguntas? ¿Cómo se hallan dispuestos los pupitres en la sala de clase? ¿Propicia la actividad del aula y de la escuela el trabajo en grupo?, etc. Uno de los ingredientes del ambiente de aprendizaje es la imputabilidad-responsabilidad.

14 Por supuesto, "cinismo" y "cínico" son expresiones usadas aquí imprecisamente. No se trata de la versión de estas ni en la tradición clásica (Diógenes), ni en la contemporánea (Onfray-Sloterdijk). Más coloquialmente se trata del que se puede Ilamar un "sinvergüenza" o un "caradura". 
Que se diseñe un ambiente de aprendizaje no implica que este pueda determinar a cada quien. Se trata, en este caso, a cada quien como última instancia del despliegue del sentido, pero, al mismo tiempo de un sujeto que tiene que operar o realizar el sentido con-los-otros $\leftrightarrow$ en-medio-de-losotros $\leftrightarrow$-pesar-de-los-otros. Otros hay, pero de lo único que cada quien se tiene que hacer responsable es de todo aquello que se le puede imputar.

Strawson (1974) mostró cómo la sensibilidad moral se basa en tres sentimientos específicos: la indignación, el resentimiento y la culpa, esto es, en la capacidad de darse cuenta de que al otro se le viola o conculca un derecho, o que es a un quién (yo) a quien se le violentan o vulneran los derechos, o que en algunos casos un quien en primera persona es quien le violenta el derecho al otro. La sensibilidad moral por sí ni es argumentación, ni es diálogo, ni es consenso, ni es acción; pero es la base para que se llegue a racionalizar la experiencia: imputabilidad-responsabilidad, punto de vista propio y curso de acción ante lo diagnosticado o comprendido. Acaso se pueda coincidir con Strawson en que la sensibilidad moral es educable: cada quien la aprende tanto como puede aprender la indolencia, la insensibilidad moral. Se trata de una suerte de "sensor" que permite reaccionar, y que lleva a reaccionar, ante lo que les hacen a los otros, lo que los otros nos hacen, lo que les hacemos a los otros.

La imputabilidad incluso puede llegar a ser evaluada legalmente; la responsabilidad, en cambio, es materia de mayor interpretación, funda el ámbito de la ética. No obstante, imputabilidad-responsabilidad pueden ser criterios para evaluar cómo va cada quien, en primera persona, en cada situación. Esta evaluación puede hacerse desde ángulos específicos como: el social, el psicológico, el cultural, el económico, el histórico; y, como ya se dijo, desde el ético o moral y el legal. Esta es la cosa misma de las humanidades, de la humanización.

\section{Aidós fuente de Dike: Úrsula}

A causa de lo cual ni nacer ni deshacer le permite Dike, aflojándole de la cadena

(DK 28 в 8, 13-14).

Lo mismo permanece en lo mismo, y descansa en sí mismo, y así permanece firme en su posición; pues la poderosa Necesidad lo mantiene en las ligaduras del límite, que lo rodea en su entorno

(DK 28 в 8, 29-31). 
Conrado Eggers Lan y Victoria E. Juliá en Los filósofos presocráticos (1986) observan sobre estos textos:

... la justicia aparece en Parménides identificada a veces con la Necesidad, aunque ésta sólo denote el aspecto de la inexorable rigidez de aquélla. [...] Dike [...] una divinidad mítica, [...] Parménides la menciona en el proemio junto a Thémis, que es la justicia personal [...], mientras Dike es la justicia impersonal de la Pólis, la justicia estatal. (pp. 453-454).

Sin memoria, sin historia, la norma termina siendo un "formalismo", vacío de contenido; de ahí que personas y empresas puedan actuar bajo la ley -incluso violándola, pero haciéndose cargo de las consecuencias-, sin vergüenza. Así, la legalidad no es necesariamente eticidad, responsabilidad, vida moral.

Lo que deviene históricamente es la justicia, más que la ley-siempre abstracta, esto es, atemporal-. Vamos a examinar este asunto siguiendo un corto fragmento de Cien años de soledad ${ }^{15}$.

Arcadio fue investido de autoridad por Victorio Medina, tras la capitulación de Neerlandia; convencionalmente, en términos predicativos, incluso, recibió un mandato: "Ahí te dejamos Macondo [...]. Te lo dejamos bien, procura que lo encontremos mejor" (p. 126).

Sobre esta base ocurre el desajuste: estar fuera de lo justo, fuera del principio de justicia. Arcadio se declara la ley, no con base en la historicidad fundada sino en la legitimidad asumida. Es intérprete del mandato que le dio Victorio Medina y se autoinstaura no solo como la fuente de la autoridad y el poder, sino también de la legalidad y la legitimidad, como en los peores episodios monárquicos, de Enrique vIII o Luis XIV: Arcadio es la ley, es el Estado. Por eso se vuelve despótico, atrabiliario.

El momento más importante del relato aludido es el devenir de la justicia basada en la vergüenza, con su moralidad y con la historia rediviva para reinstaurar la autoridad que basa la justicia en la ética. Es lo que viene a ser Úrsula, una anciana que coge tan solo un "rebenque alquitranado" (p. 127), a diferencia de las armas que porta el pelotón: las piezas de artillería, el sable, las escopetas...

Úrsula con su modesto rebenque no solo reduce a Arcadio a una posición fetal, en forma de caracol, sino que lo deja sujeto a Dike; también reduce el pelotón sobre el cual tiene mando Arcadio. De tal manera que Dike no solo vale para el hijo, sino para todos sus subordinados. De estos, ninguno atina a defender al líder; antes bien todos deciden acatar la moralidad o justicia de Aidós-Dike-Úrsula. 
Úrsula conmina a Arcadio con estas palabras:

-¡Atrévete, bastado! -gritó Úrsula.

Antes de que Arcadio tuviera tiempo de reaccionar, le descargó el primer vergajazo. "Atrévete, asesino", gritaba. Y mátame también a mí, hijo de mala madre. "Así no tendré ojos para llorar la vergüenza de haber criado un fenómeno". Azotándolo sin misericordia, lo persiguió hasta el fondo del patio, donde Arcadio se enrolló como un caracol. (p. 127).

Aquí está el núcleo del reclamo ético. En Úrsula-Aidós-Dike, hacía eco para esta acción deliberada el hecho de que la travesía de los Buendía empezó cuando José Arcadio mató al gallero Prudencio Aguilar; después de este gesto, José Arcadio regresó a su casa y forzó al sexo -temido por la relación de parentesco- a Úrsula; y empezó la progenie de los Buendía. Fueron la muerte del gallero y la evidencia de la progenie, dos expresiones de la vergüenza, las que sostuvieron la travesía y la fundación de Macondo.

Úrsula hace la reprimenda referida a Arcadio en vista de los costos que trae un asesinato: el de Prudencio Aguilar, una vergüenza que siempre se cernió sobre la mente de José Arcadio, incluso en algunos de los breves momentos de lucidez atado al castaño, en donde era uno de sus interlocutores, al lado de Melquíades.

La moral queda sintetizada como fundamento de la justicia en una única expresión que ancla la posibilidad del juicio ético: la vergüenza (Aidós). Úrsula-Aidós-Dike pone a Arcadio en la encrucijada de ser un hombre con vergüenza (sensibilidad moral) o un sinvergüenza (indolencia moral). La diferencia entre el actuar legal o legítimo y el actuar ético o moral radica en que el referente de este juicio y de esta acción sea o no la vergüenza (Aidós fuente de Dike).

La eudaimonía es el fin al que se aspira y que, solo en el juego, se realiza plenamente; en el éxtasis que implica el juego. Sin embargo, para lograr el mentado éxtasis se exige pasar por el fundamento del trabajo y del sacrificio en el origen que ofrece la areté; esta, incluso, genera la cuestión de la imputabilidad y de la reprimenda. A partir de aquí se puede notar que Úrsula las diferencia, al imponer un horizonte emocional a su acción ética; esto solo se deja indicado, no resuelto, pese a que se opta por una metafísica levinasiana que exige el "deseo" de la alteridad.

Tanto si la acción se orienta a la eudaimonía como a la areté, la cuestión de la educación es una clave fundamental para su despliegue. Aunque esto se enuncia en este apartado, lo que se elabora al respecto en este artículo solo se verá en el siguiente apartado. 


\section{Juego como resistencia}

El capitalismo tardío de Occidente lo captura todo, biopolíticamente, mediante el mercado ${ }^{16}$. El sentido último de las humanidades es el reconocimiento del otro (en y desde la Radicalidad del Otro), en una puesta más allá del mercado, en las márgenes, con actos innovadores de resistencia, una y otra vez. Esto implica pensar las humanidades, contemporáneamente, desde la restancia, la alteridad, el excluido, siempre que no se ideologice $y$, en consecuencia, que se lo reconozca en actitud desencubridora y anárquica. Y, desde luego, esto es un juego, que implica ocio, que parte "del contacto colectivo con el prójimo" (Fink, 1966, p. 7), en y para "el goce de la acción lúdica" (p. 8). Se trata de un "juego humano [...] profundo y secreto [...] [,] adulto" (p. 10) que ofrezca "un oasis infrecuente" a la "huida incesante" (p. 15) en que él vive.

La reivindicación del juego como resistencia parte de hallarse "gozosamente [...] movido en sí con alegría, alado" (p. 17), hasta encontrar en el juego mismo el sentido (p. 18) que permita constituir una "comunidad lúdica" (p. 18). Ahora bien, propio del juego es que tenga siempre como polo recíproco no solo al otro, sino también al juguete (p. 19). Este puede ser o no artificial (p. 20). En todo caso, en el juguete radica el carácter mágico del juego (p. 20). No hay juego en el que no haya "papeles de los jugadores, [...] papeles alternativos de la comunidad lúdica, [...] obligatoriedad de la regla de juego, [...] significación del juguete" (p. 21). Aquí se despliega "el elemento de la libertad" (p. 23).

Se juega siempre con otros. Se puede capturar el juego hasta hacer de él una patología (ludopatía, con ludópatas). Se puede capturar el juguete, hasta volverlo un dispositivo de captura de la subjetividad; y, entonces, reducir el juguete a un valor de cambio.

$\mathrm{O}$, en y desde la resistencia, se trata de jugar al juego que en cada momento realiza la existencia: en el trabajo, en la lucha, en el amor, en la muerte. Si se retorna al juego, a su inmanencia, se rompe con la seriedad del negocio y se llega al oasis de la felicidad: el juego. También en el trabajo, sin la trascendencia de los afanes, se entra en juego: con los otros, con el sentido que unos y otros dan al paso de las horas; ni qué decir en el amor: se juega una y otra vez hasta poder hallarse ante el sentido de sí y del otro, en la confluencia de sus existencias. Y las batallas, el sentido agonal de la experiencia de mundo, son serias porque las jugamos en serio, y les damos un sentido. Y es la muerte el juego último, que tomado con seriedad, como juego, pierde su trascendencia porque se muestra inmanentemente, como lo que, sin más, irremediablemente pasa en el juego de la vida. 
Eugen Fink (p. 29) invoca tanto a Heráclito como a Nietzsche: el curso del mundo es un niño que juega; este mundo, eterno juego del artista y del niño. Y cierra su análisis indicando, novotestamentariamente, que "no podremos entrar en el reino de los cielos, si no nos hacemos como niños" (p. 30). ¿Qué es, pues, la resistencia que ofrece y se abre desde el juego? En último término, la íntima responsabilidad de abandonar la seriedad de

... la teología política, que funda en el Dios único la trascendencia del soberano, y la teología económica, que la sustituye con la idea de una oikonomia, concebida como un orden inmanente -doméstico y no político en sentido estricto- tanto en la vida política como humana. (Agamben, 2008, p. 17).

El juego -las reglas de juego- es cosa humana, no divina. De hacer vida esta verdad es de lo que se trata cuando se apunta a la ontología del juego como fundamento de la existencia, pues "la apertura a otros jugadores posibles está ya implícita en el sentido del juego" (p. 18); el juego siempre exige "un jugador real, si ha de tratarse de un real y no sólo pensado. Además es esencial el momento de la regla de juego" (p. 19).

Pero, ¿dónde es que se funda la resistencia, en el juego? En síntesis, el hecho de que "la regla de juego no es una ley. La obligación no tiene carácter inmutable. Aun dentro del curso de la acción lúdica podemos cambiar las reglas, si contamos con el consentimiento de los compañeros de juego" (p. 19). Este es el corazón de la resistencia: las reglas -que no son leyes-son inmanentes al juego, a la interacción de los jugadores en el juego; y siempre se pueden redefinir. La seriedad del juego -que se oculta con la presunta seriedad de los negocios, del trabajo- radica en que los que intervienen siempre se pueden habilitar como críticos, deconstructores, anárquicos frente al orden establecido.

La resistencia, el juego como resistencia, lo que enseña es que el status quo es un mero efecto y que siempre, en todas las circunstancias, las cosas pueden ser de otra manera. El juego es el principio anárquico que descubre que todo puede ser puesto en discusión; incluso el juego mismo.

Las humanidades, que buscan humanizar la experiencia de mundo, son el juego que deliberadamente procura el acceso al otro, la Radicalidad del Otro, en su misterio e inagotabilidad. Es la renuncia a todo proyecto positivista (en ciencias, en el derecho, en el arte, etc.) de instauración de una "ley" que impere como único esquema de relación con el otro. Las humanidades, como juego de despliegue de los unos con los otros, se tornan ética del reconocimiento; y, por eso mismo, principio anárquico de deconstrucción y de destrucción de la totalidad; es aspiración a la infinitud del otro.

Concluyamos este estudio indicando que este juego, con el Estado, la razón de Estado (con su derecho y sus ciencias positivas, sean antihumanistas o poshumanistas) puede ser una y otra vez jugado como lo enseñó Kant:

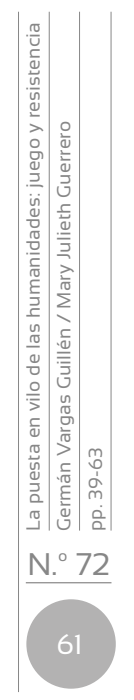


... puesto que el político práctico [y, agregamos nosotros, el "científico" apoltronado en su desprecio a las humanidades] acostumbra desdeñar, orgulloso, al teórico [esto es, al humanista], considerándole como un pedante inofensivo, cuyas ideas desprovistas de toda realidad no pueden ser peligrosas para el Estado, que debe regirse por principios fundados en la experiencia; puesto que el gobernante, "hombre experimentado", deja al teórico jugar su juego, sin preocuparse de él, cuando ocurra entre ambos un disentimiento deberá el gobernante ser consecuente y no temer que sean peligrosas para el Estado unas opiniones que el teórico se ha atrevido a concebir, valgan lo que valieren. (1972, p. 215).

\section{Referencias}

Agamben, G. (2008). El reino y la gloria. Para una genealogía teológica de la economía y del gobierno. Valencia: Pre-Textos.

Fink, E. (1966). (E. C. Frost, trad.). Oasis de la felicidad. Pensamientos para una ontología del juego. Cuaderno 23. Centro de Estudios filosóficos. México: Universidad Autónoma de México.

Foucault, M. (1966/1968, en español). Las palabras y las cosas. Buenos Aires: Siglo xxı.

Foucault, M. (1974). (E. C. Frost, trad.). Las palabras y las cosas. Una arqueología de las ciencias humanas. México: Siglo xxı.

García Márquez, G. (2007). Cien años de soledad. [Edición de la Real Academia Española]. Bogotá: Norma,

Habermas, J. (1988). La lógica de las ciencias sociales. Madrid: Tecnos.

Habermas, J. (2014). (M. Jiménez Redondo, trad.). Teoría de la acción comunicativa. Madrid: Trotta.

Hofmeyr, B. (2009). Radical passivity. The Netherlands: Springer.

Husserl, E. (2008). (J. V. Iribarne, trad.). La crisis de las ciencias europeas y la fenomenología trascendental. Buenos Aires: Prometeo

Kant, I. (1972). (F. Rivera Pastor, trad.). Fundamentación de la metafísica de las costumbres. Crítica de la razón práctica. La paz perpetua. México: Porrúa.

Kohlberg, L. (1981). Education for Justice: A Modern Statement of the Socratic View, Essays on Moral Development. Volume One: The Philosophy of Moral Development, Moral Stages and the Idea of Justice (Chapter 2, pp. 29-48). San Francisco, Harper \& Row Publishers. Reimpresión, a su vez, de: Sizer, N. \& Sizer, T. (eds.), (1970). Moral Education: Five Lectures. Cambridge: Harvard University Press.

Lacan, J. (1983). (I. Agoff, trad.). ¿Dónde está la palabra? ¿Dónde está el lenguaje? En: El yo en la teoría de Freud y en la técnica psicoanalítica (19541955). El seminario de Jacques Lacan. Libro 2. Buenos Aires: Paidós. 
Lacan, J. (1989). (T. Segovia, trad.). El tiempo lógico y el aserto de certidumbre anticipada. Un nuevo sofisma. En: Escritos 1. México: Siglo xxı.

Lacan, J. (1999). (E. Berenguer, trad.). El deseo del Otro. En Las formaciones del inconsciente. (1957-1958). El seminario de Jacques Lacan. Libro 5. Buenos Aires: Paidós.

Levinas, E. (1974). (D. E. Guillot, trad.). Humanismo del otro hombre: España: Siglo xxı de España Editores.

Los filósofos presocráticos. (1986). (C. Eggers Lan y V. E. Juliá, trad., introducción y notas). Madrid: Gredos.

Manifiesto contra el asesinato de la filosofía en Colombia; cf. https: // profesorvargasguillen.files.wordpress.com/2014/09/manifiesto-contra-el-asesinato-de-la-filosofc3ada-en-colombia.pdf. [Consultado el 31 de julio de 2016].

Openheimer, A. (2010). ¡Basta de historias! La obsesión latinoamericana con el pasado y las 12 claves del futuro. Debate.

Piaget, J. (1965/1970, español). Sabiduría e ilusiones de la filosofía. Barcelona: Sígueme.

Piaget, J. (1973). Tendencias de la investigación en ciencias sociales. Madrid: Alianza.

Strawson, P. F. (1974). Freedom and resentment and other essays. Londres: Methuen.

Tengelyi, L. (2010). La fenomenología como filosofía primera. En: Devenires, $x ı(21), 115-131$.

Vargas Guillén, G. (2012). Fenomenología, formación y mundo de la vida. Saarbrücken, EAE.

Vargas Guillén, G. (2016a). El deseo y la formación. Bogotá: Aula de Humanidades.

Vargas Guillén, G. (2016b). Pasividad: constitución e individuación. En: La experiencia que somos. Metafísica, fenomenología y antropología (pp. 87 a 105). México: Centro Mexicano de Investigaciones Fenomenológicas.

Vargas Guillén, G. y Hoyos, G. (1997). La teoría de la acción comunicativa como nuevo paradigma de investigación en ciencias sociales: las ciencias de la discusión. Bogotá: Editorial Icfes.

Wallerstein, E. (1996). Abrir las ciencias sociales. Madrid: Siglo xxı. 